\title{
Hot-pressed Chromium Doped Zinc Sulfide Infrared Transparent Ceramics
}

\author{
Yiyu Li ${ }^{1}$, Yin Liu ${ }^{1}$, Vladimir V. Fedorov ${ }^{2}$, Sergey B. Mirov ${ }^{2}$, and Yiquan Wu ${ }^{1, *}$ \\ ${ }^{1}$ Kazuo Inamori School of Engineering, New York State College of Ceramics, Alfred University, \\ Alfred, NY 14802, USA \\ ${ }^{2}$ Center for Optical Sensors and Spectroscopies and the Department of Physics, University of \\ Alabama at Birmingham, CH 310, 1300 University Blvd., Birmingham, AL 35294, USA \\ *corresponding author. Contacts: e-mail: wuy@alfred.edu; phone number: +01-607-871-2662; \\ address: 2 Pine Street, Alfred, New York, 14802, USA.
}

\begin{abstract}
The present study, for the first time, reports the successful consolidation of chromium doped zinc sulfide (ZnS) polycrystalline infrared (IR) transparent ceramics (maximum transmittance of $67 \%$ at $11.6 \mu \mathrm{m}$ ) via hot pressing under vacuum. The phase composition of the as-sintered $\mathrm{Cr}^{2+}: \mathrm{ZnS}$ ceramics was determined to be primarily cubic $\mathrm{ZnS}$ sphalerite, with a minor amount of hexagonal $\mathrm{ZnS}$ wurtzite. Scanning electron microscopy (SEM) observation of the sintered ceramics showed a highly consolidated microstructure. IR absorption and photoluminescence measurements revealed that the $\mathrm{Cr}^{2+}$ ions are tetrahedrally coordinated within the $\mathrm{ZnS}$ host lattice.
\end{abstract}

Keywords: Hot pressing; Ceramics; Optical spectroscopy; Optical properties; Chromium doped $\mathrm{ZnS}$

As an extensively characterized II-VI wide bandgap semiconductor, zinc sulfide has been of significant interest for a long time due to its promising applications in various fields, including optical ceramics, phosphors, quantum dots, photocatalysts, and sensors [1-4]. When doped with transition metals and rare earth elements, $\mathrm{ZnS}$ can exhibit a wide range of luminescence behaviors in the visible and infrared regions [5-9]. In addition, due its exceptional performance as a material for room-temperature tunable solid state laser gain media in the mid-IR region, transition metal doped $\mathrm{ZnS}$ has inspired a tremendous amount of interest for researchers in past decades.

In 1996, researchers at Lawrence Livermore National Laboratory demonstrated the potential of divalent transition metal doped zinc chalcogenides as materials for mid-IR laser applications 
[10]. Various divalent transition metals $\left(\mathrm{Co}^{2+}, \mathrm{Ni}^{2+}, \mathrm{Fe}^{2+}\right.$ and $\left.\mathrm{Cr}^{2+}\right)$ were doped into $\mathrm{ZnS} / \mathrm{ZnSe} / \mathrm{ZnTe}$ hosts, and their room temperature mid-IR lasing performances were examined. It was determined that the tetrahedral substitution sites, rather than the octahedral sites, are more favorable doping sites for transition metals in the zinc chalcogenides. The tetrahedral coordination of dopants might contribute to the observed intense low-energy transitions, due to small crystal field splitting. Among the $\mathrm{Zn}$ chalcogenides, $\mathrm{Cr}^{2+}$ doped $\mathrm{ZnS} / \mathrm{ZnSe}$ showed exceptionally strong room-temperature absorption and emission in the mid-IR region. In addition, temperature-dependent lifetime measurements indicated that these materials revealed high (close to 80 and $100 \%$ for $\mathrm{Cr}: \mathrm{ZnS}$ and $\mathrm{Cr}: \mathrm{ZnSe}$, respectively) luminescence quantum yield at room temperature due to weak non-radiative relaxation process [1,2]. It was demonstrated that $\mathrm{Cr}^{2+}$ doped $\mathrm{ZnS} / \mathrm{ZnSe}$ crystals were the most promising candidates for room-temperature tunable mid-IR laser applications. Since then, chromium doped $\mathrm{ZnS}$ has attracted more and more extensive attention.

Mirov et al. have conducted tremendous research on the lasing performances of $\mathrm{Cr}^{2+}: \mathrm{ZnS}$ materials [11-14]. It has been reported that they applied chemical vapor transport (CVT) methods followed by thermal diffusion to fabricate $\mathrm{Cr}^{2+}: \mathrm{ZnS}$ transparent ceramic microchips with desirable lasing performances (optical and slope efficiency) [15]. It was also demonstrated by Wang et al. that $\mathrm{Cr}^{2+}: \mathrm{ZnS}$ thin films with promising properties for mid-IR applications could be prepared by pulsed laser deposition [16]. In addition, Martyshkin et al. investigated and demonstrated the effective photoluminescence and lasing properties of $\mathrm{Cr}^{2+}: \mathrm{ZnS}$ nanoparticles in the mid-IR region [17]. Meanwhile, by using Cr:ZnS single crystals , Tolstik et al. obtained Kerr-Lens passive mode-locked Cr:ZnS femtosecond lasers, with distinguished pulse duration and energy [18, 19]. The output characteristics of Kerr-lens-mode-locking were significantly improved in [20-22] with the use of $\mathrm{Cr}: \mathrm{ZnS}$ polycrystalline gain media. Besides studying the lasing performance of $\mathrm{Cr}^{2+}: \mathrm{ZnS}$, a significant amount of research has been conducted towards understanding the material, including the theory surrounding its crystal field splitting and local structure, as well as its potential applications in other fields such as cathodoluminescence and solar cell applications [23-26].

The most commonly reported method to fabricate $\mathrm{Cr}^{2+}: \mathrm{ZnS}$ transparent materials for laser applications is CVT method followed by thermal diffusion [27]. In addition, based on the method 
employed to process $\mathrm{ZnS}$ transparent ceramics, CVD combined with hot isostatic press (HIP) has also been used to prepare polycrystalline $\mathrm{ZnS}$ host ceramics prior to the thermal diffusion of $\mathrm{Cr}^{2+}$ ions [28]. However, these methods are expensive and time-consuming, and have poor repeatability. As a common consolidation method, it is well known that hot pressing has been proven to be an effective and viable way to prepare various optically transparent non-oxide and oxide ceramics, such as $\mathrm{ZnS}, \mathrm{CaF}_{2}, \mathrm{Y}_{2} \mathrm{O}_{3}, \mathrm{Lu}_{2} \mathrm{O}_{3}$, and $\mathrm{MgAl}_{2} \mathrm{O}_{4}$ [29-36]. It has also been demonstrated that $\mathrm{Cr}^{2+}: \mathrm{ZnSe}$ transparent ceramics with suitable properties for laser applications can be fabricated via hot pressing [37]. However, few studies have been reported on the hot pressing of $\mathrm{Cr}^{2+}: \mathrm{ZnS}$ transparent ceramics.

In the present study, $\mathrm{Cr}^{2+}: \mathrm{ZnS}$ IR transparent ceramics were fabricated via high vacuum hot pressing (VHP) using homogeneous ZnS powders synthesized using a wet chemical precipitation route, which were subsequently mixed with commercially sourced $\mathrm{Cr}_{2} \mathrm{~S}_{3}$ powders. It was determined that the sintered $\mathrm{Cr}^{2+}: \mathrm{ZnS}$ ceramics were primarily composed of cubic sphalerite phase, with hexagonal wurtzite as a minor phase. The ceramics were studied using SEM, and found to be well-consolidated and highly dense. The spectroscopic properties of the material were characterized to investigate the mid-IR absorption and photoluminescence behavior induced by doping with $\mathrm{Cr}^{2+}$.

The synthesis of $\mathrm{ZnS}$ powders was performed through a facile colloidal processing method, which was reported in our previous studies [31]. Aqueous solutions of thioacetamide (TAA, $\geq 99.0 \%$, Sigma Aldrich) and $\mathrm{Zn}\left(\mathrm{NO}_{3}\right)_{2} \cdot 6 \mathrm{H}_{2} \mathrm{O}(\geq 99.0 \%$, Sigma Aldrich) with stoichiometric ratios of $\mathrm{Zn}: \mathrm{S}$ were mixed together by stirring, and $\mathrm{HNO}_{3}(70 \%$, Sigma Aldrich) was added to the mixed solution to adjust $\mathrm{pH}$ to 2 . The solution was then heated in a hot water bath to encourage particle growth. After sufficient time, the suspension of $\mathrm{ZnS}$ colloids was cooled in an ice water bath to halt particle growth. The precipitates were then washed by both DI water and ethanol (Reagent alcohol, $100 \%$, Decon) to remove reaction residues, and then dried in an oven in air. The precipitates were then finely ground and mixed with an addition of $0.1 \mathrm{~mol} \% \mathrm{Cr}_{2} \mathrm{~S}_{3}$ (99\%, Alfa Aesar) in an agate mortar and pestle. The mixed powders were then heat treated at $900{ }^{\circ} \mathrm{C}$ for 4 hours in flowing argon to prepare for sintering. The ceramic samples were prepared for VHP by loading the powders into a graphite die with a diameter of $10 \mathrm{~mm}$, with layers of graphite foil (thickness of $0.5 \mathrm{~mm}$ ) used to separate the sample powders from the punches. The powders were 
consolidated at $1000^{\circ} \mathrm{C}$ for 2 hours under a uniaxial pressure of $50 \mathrm{MPa}$ under a vacuum of $10^{-5}$ mbar (OTF-1200X-VHP4, MTI).

The phase composition of the sintered $\mathrm{Cr}^{2+}: \mathrm{ZnS}$ ceramics was determined using XRD (Bruker D2 PHASER) with $\mathrm{Cu} K \alpha(\lambda=0.154 \mathrm{~nm})$ radiation at a voltage of $30 \mathrm{kV}$ and a current of $10 \mathrm{~mA}$. Measurement conditions of $0.03^{\circ} 2 \theta$ step size and $0.2 \mathrm{~s}$ count time were employed over a measurement range of $10-75^{\circ} 2 \theta$. The morphological and structural features of the Cr:ZnS powders and sintered ceramics were investigated by SEM (FEI Quanta 200) at an accelerating voltage of $20 \mathrm{kV}$. Archimedes's method density measurements were adopted to determine the density of the as-sintered ceramics. The IR transmittance of the polished pellet was measured using FTIR (Nicolet 6700, Thermo Fisher). Photoluminescence spectra and kinetics characterizations were performed using an acousto-optically Q-switched Er:YAG laser under an excitation at $1.645 \mu \mathrm{m}$ with $\sim 60 \mathrm{~ns}$ pulse duration. Photoluminescence spectra were collected by using a monochromator (Acton Research ARC-300i). A Thorlabs PDA 20H PbSe detector, in addition to a fast PVI-3TE-5 (HgCdTe, VIGO systems) detector with a response time of $\sim 200 \mathrm{~ns}$ were employed for signal detection. A polycrystalline $\mathrm{Cr}^{2+}: \mathrm{ZnS}$ sample with a chromium concentration of $8 \cdot 10^{18} \mathrm{~cm}^{-3}$, fabricated by a post-growth thermal diffusion method [12], was used for the comparison of optical properties with the $\mathrm{Cr}^{2+}: \mathrm{ZnS}$ ceramics.

Fig.1 (a) shows the SEM image of the synthesized $\mathrm{ZnS}$ powders mixed with a $0.1 \mathrm{~mol} \%$ addition of $\mathrm{Cr}_{2} \mathrm{~S}_{3}$ powders. The powders appear to be composed of well-dispersed, homogenous, spherical particles with a size of approximately $100-200 \mathrm{~nm}$, the small size of which is attributed to the use of both hot and cold water baths to achieve better control of particle growth during colloidal processing. The microstructure of the thermally etched surface of the polished $\mathrm{Cr}^{2+}: \mathrm{ZnS}$ ceramics is shown in Fig. 1 (b). It can be observed that the VHP-consolidated ceramics have an average grain size of about 1-2 $\mu \mathrm{m}$ and is highly dense, likely due to the homogenous morphology of the raw powders and the effectiveness of applied VHP technique. The relative density was measured to be $98.8 \%$, which is in agreement with SEM observations of a highly consolidated microstructure. Fig. 1 (c) displays the XRD pattern of the $\mathrm{Cr}^{2+}: \mathrm{ZnS}$ ceramics consolidated via VHP. The sample is composed of a mixture of mainly cubic sphalerite (JCPDS no: 65-5476; F-43m; a=5.40 Á) with a small amount of hexagonal wurtzite (JCPDS no: 02-1310; P63mc; $\mathrm{a}=3.82 \AA$ \&́, $\mathrm{c}=6.25 \AA$ ). . In addition, no $\mathrm{Cr}_{2} \mathrm{~S}_{3}$ impurity peaks can be detected in the XRD 
measurement because of the low added level of $\mathrm{Cr}_{2} \mathrm{~S}_{3}$. Due to the high surface energy of the small particles of the raw powders, during consolidation the $\mathrm{Cr}^{2+}: \mathrm{ZnS}$ ceramics experience an early phase transition from the cubic phase to hexagonal phase at $1000{ }^{\circ} \mathrm{C}$, which is lower than the reported phase transition temperature of $1020^{\circ} \mathrm{C}$.
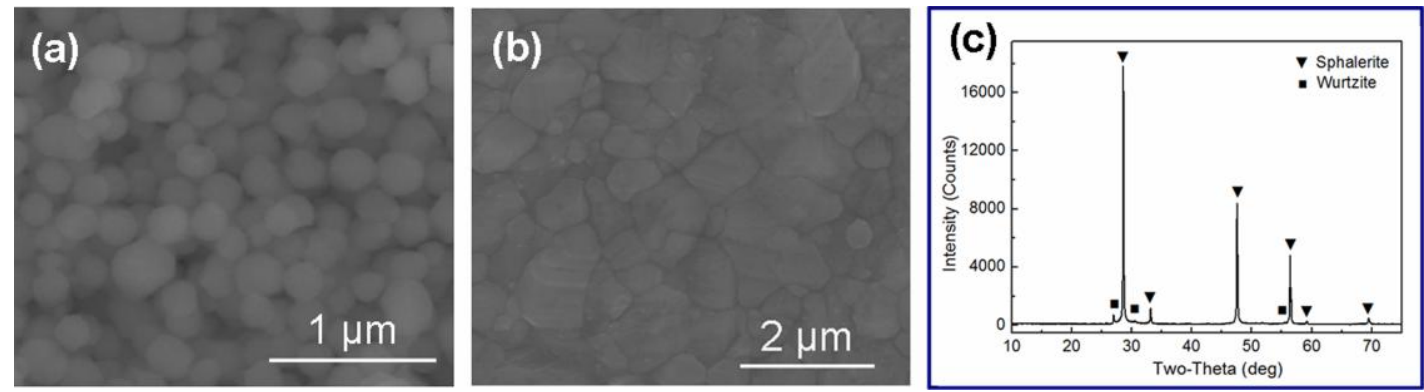

Fig. 1. (a) SEM image of the synthesized $\mathrm{ZnS}$ powders mixed with $0.1 \mathrm{~mol} \% \mathrm{Cr}_{2} \mathrm{~S}_{3}$ powders. (b)

SEM image of the thermally etched surface of the VHP-sintered $\mathrm{Cr}^{2+}: \mathrm{ZnS}$ ceramics. (c) XRD pattern of the $\mathrm{Cr}^{2+}: \mathrm{ZnS}$ ceramics consolidated via VHP.

Fig. 2 (a) shows the IR transmittance curve of a polished $\mathrm{Cr}^{2+}: \mathrm{ZnS}$ ceramic pellet, obtained by FTIR measurement over a wavelength range of 2.5-16.0 $\mu \mathrm{m}$. Due to the effective consolidation via VHP, the $\mathrm{Cr}^{2+}: \mathrm{ZnS}$ polycrystalline ceramic sample exhibits high transmittance in the IR region, with a maximum transmittance of $67 \%$ at $11.6 \mu \mathrm{m}$, while the theoretical maximum transmittance according to the Fresnel's equations is $75 \%$ in the IR range. It is important to note that the transmission curve shape near the IR edge is very similar for the VHP-consolidated ceramic sample and the polycrystalline sample fabricated via the post-growth thermal diffusion method. The reduced transmission observed in the VHP-consolidated ceramic sample in the near-IR spectral range is likely due to scattering effects within the ceramic. As can been observed from the inset photo, the sample is translucent even in the visible region, with the green color of the sample believed to result from the incorporation of $\mathrm{Cr}^{2+}$ ions into the $\mathrm{ZnS}$ lattice. Based on comparison of spectra from measurement of the samples and measurement of the ambient atmosphere, it is determined that the absorption peaks in the 3.2-7.0 $\mu \mathrm{m}$ range are due to atmospheric absorptions. Specifically, the absorption bands between $3.4,3.5$ and $4.2 \mu \mathrm{m}$ are attributed to water adsorbed from the atmosphere, and the small peaks at 5.7, 6.2 and $7.0 \mu \mathrm{m}$ correspond to the $\mathrm{C}=\mathrm{O}$ stretching modes of $\mathrm{CO}_{2}$ adsorbed from the ambient atmosphere. $\mathrm{ZnS}$ characteristic vibrations lead to the 
band at $15.2 \mu \mathrm{m}$ [9]. In addition, the absorption peak at 9.1 and $10.9 \mu \mathrm{m}$ can be probably attributed to $\mathrm{ZnS}$ precursor residuals in the colloidal processing route or carbon contamination from graphite during the VHP process [30, 31].

The near-IR transmittance curve of the sample is shown in Fig. 2 (b). Dotted line shows the baseline from the FTIR measurement of the ambient atmosphere. As can be determined from the transmittance plot, the VHP-sintered ceramic sample features a very strong scattering effect. It is important to note that the broad band at $1690 \mathrm{~nm}$ corresponds to the ${ }^{5} \mathrm{~T}_{2} \rightarrow{ }^{5} \mathrm{E}$ absorption band from the split ground state ${ }^{5} \mathrm{D}$ of $\mathrm{Cr}^{2+}$, which confirms that $\mathrm{Cr}^{2+}\left(3 \mathrm{~d}^{4}\right)$ is incorporated into the lattice of the $\mathrm{ZnS}$ host in a site with tetrahedral coordination [38]. In addition, the $\mathrm{Cr}^{2+}$ concentration of the $\mathrm{Cr}^{2+}: \mathrm{ZnS}$ ceramic can be estimated from the absorption peak at $1690 \mathrm{~nm}$. First, the active absorption coefficient at $1690 \mathrm{~nm}$ can be obtained according to Beer Lambert Law:

$$
\alpha=-\operatorname{Ln}(T) / d
$$

where $\alpha$ is the active absorption coefficient, $T$ corresponds to the normalized transmittance ratio, and $d$ is the thickness of the sample $(0.07 \mathrm{~cm})$. Here, we can estimate $T$ to be 0.88 , based on comparison of the actual measured transmittance at $1690 \mathrm{~nm}$ with the estimated baseline of the transmittance curve between $1400 \mathrm{~nm}$ and $2000 \mathrm{~nm}$. After obtaining the active absorption coefficient at $1690 \mathrm{~nm}$, the concentration of $\mathrm{Cr}^{2+}$ can be estimated by the following relation:

$$
N=\alpha / \sigma
$$

where $N$ is the concentration of the ion, and $\sigma$ refers to the absorption cross-section. It has been reported that the absorption cross-section of $\mathrm{Cr}^{2+}: \mathrm{ZnS}$ at $1690 \mathrm{~nm}$ is $1.0 \times 10^{18} \mathrm{~cm}^{2}$ [39]. Thus, the $\mathrm{Cr}^{2+}$ concentration can be calculated as $1.8 \cdot 10^{18} \mathrm{~cm}^{-3}$ (sufficient for laser materials). However, the concentration is much smaller than the total concentration of $\mathrm{Cr}$ originally introduced into the material, which suggests that the incorporated $\mathrm{Cr}$ ions may have different valence states other than 2+. Due to the reducing nature of the high vacuum and carburizing environment due to the presence of graphite in the VHP chamber, some $\mathrm{Cr}^{3+}$ ions from the added $\mathrm{Cr}_{2} \mathrm{~S}_{3}$ are reduced to $\mathrm{Cr}^{2+}$ ions, which are then incorporated into the $\mathrm{ZnS}$ host lattice, but a portion of the $\mathrm{Cr}^{3+}$ ions from the $\mathrm{Cr}_{2} \mathrm{~S}_{3}$ may still persist in the material. In addition, it is also revealed by a preliminary X-ray photoelectron spectroscopy characterization that there are some mixed valence states of $\mathrm{Cr}$ ions including $2+$ and $3+$ within the VHP-sintered ceramic. Future research is required to determine the 
location and valence states of the chromium ions in VHP-sintered Cr:ZnS ceramics.
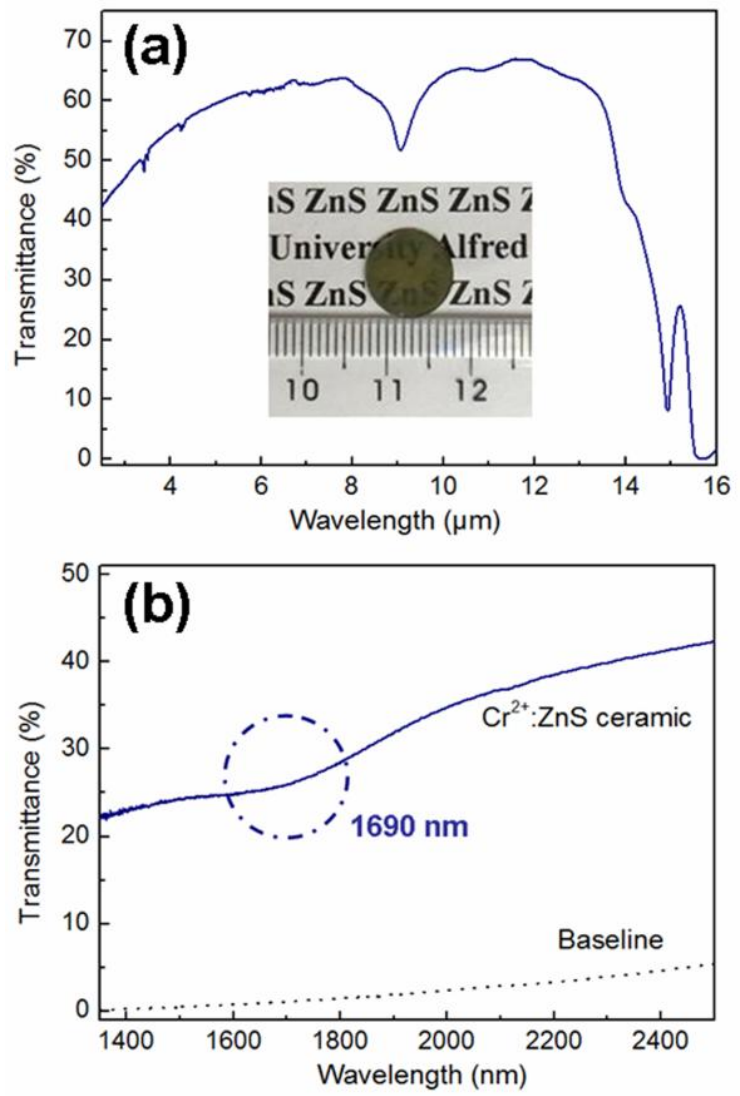

Fig. 2. (a) Room-temperature IR transmittance spectrum of the mirror-polished $\mathrm{Cr}: \mathrm{ZnS}$ ceramic, with a photograph of the sample (inset) with a diameter of $10 \mathrm{~mm}$ and a thickness of $0.7 \mathrm{~mm}$. (b) Room-temperature near-IR transmittance spectrum of the $\mathrm{Cr}: \mathrm{ZnS}$ ceramic.

Further characterization of the VHP-sintered $\mathrm{Cr}^{2+}: \mathrm{ZnS}$ ceramic sample's mid-IR optical behaviors was performed to investigate the IR photoluminescence emission and corresponding emission kinetics of the $\mathrm{Cr}^{2+}: \mathrm{ZnS}$. Fig. 3 (a) shows the room-temperature non-calibrated IR photoluminescence spectrum of the VHP-sintered ceramic under $1645 \mathrm{~nm}$ excitation. The sample exhibits the characteristic $\mathrm{Cr}^{2+}$ IR photoluminescence band from $2000 \mathrm{~nm}$ to $2200 \mathrm{~nm}$, which is attributed to the ${ }^{5} \mathrm{E} \rightarrow{ }^{5} \mathrm{~T}_{2}$ electronic transition, as a result of the cubic tetrahedral crystal splitting of the 3d-levels of $\mathrm{Cr}^{2+}\left(3 \mathrm{~d}^{4}\right)$ in $\mathrm{ZnS}$ [40]. In addition, as discussed in the aforementioned XRD analysis, both the cubic $\mathrm{ZnS}$ sphalerite phase and the hexagonal $\mathrm{ZnS}$ wurtzite phase are present in the ceramic. The difference in crystal structure and symmetry of these two phases may lead to polarization dependence of fluorescence [41], which in turn results in the asymmetric photoluminescence band shown in the emission spectrum [42, 43]. Fig. 3 (b) shows the IR 
photoluminescence kinetics of the VHP-sintered $\mathrm{Cr}^{2+}: \mathrm{ZnS}$ sample measured at room temperature under $1645 \mathrm{~nm}$ excitation. The red curve shows the detector response time measured at the excitation wavelength for comparison. From the blue fitted (Eq. (3)) exponential decay curve shown in the spectrum, it is revealed that the sample exhibits a single exponential decay process with a lifetime of $\tau=5.5 \mu \mathrm{s}$, which is consistent with previously reported decay times of the $\mathrm{Cr}^{2+}$ ${ }^{5} \mathrm{E} \rightarrow{ }^{5} \mathrm{~T}_{2}$ electronic transition in $\mathrm{Cr}^{2+}: \mathrm{ZnS}[38]$.

$$
I(t)=A \exp (t / \tau)
$$

Where $I(t)$ refers to the time-dependent luminescence intensity, $A$ is a pre-exponential weight factor, and $t$ corresponds to the actual time, and $\tau$ is the decay time. This further demonstrates that the $\mathrm{Cr}^{2+}$ ions are tetrahedrally coordinated in the VHP-sintered $\mathrm{Cr}^{2+}: \mathrm{ZnS}$ ceramic.
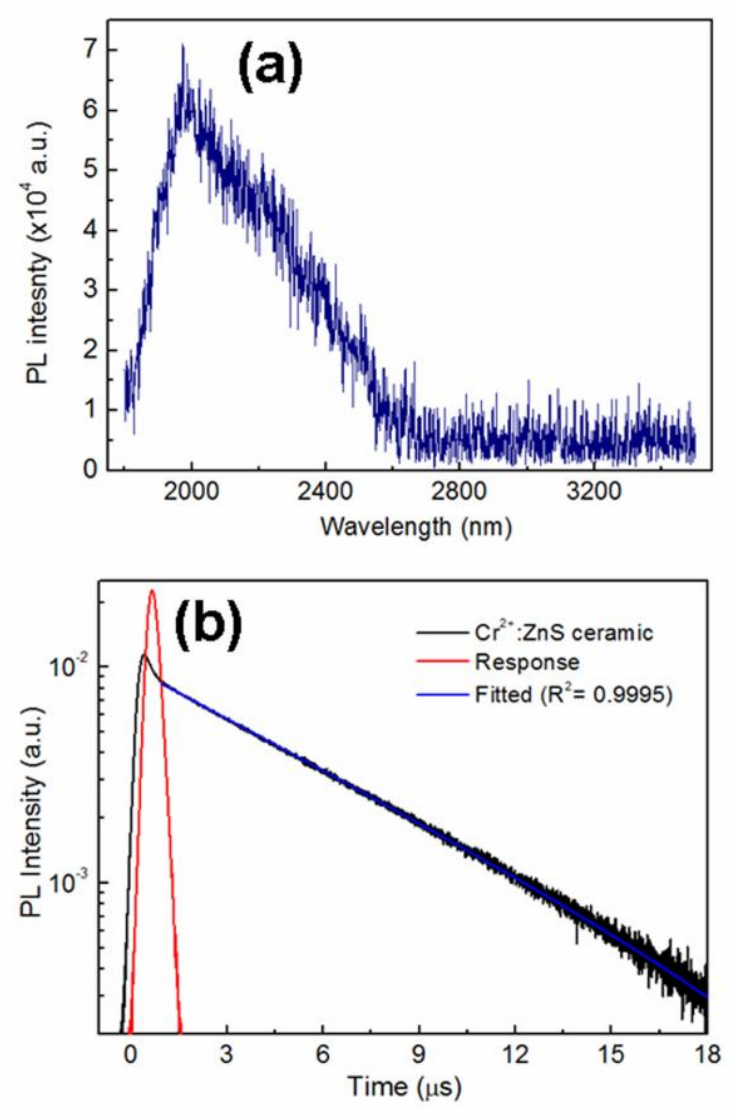

Fig. 3. (a) Room-temperature IR photoluminescence spectrum and (b) room-temperature IR photoluminescence kinetics of the VHP-sintered $\mathrm{Cr}^{2+}: \mathrm{ZnS}$ ceramic sample excited under $1645 \mathrm{~nm}$ excitation.

In summary, $\mathrm{Cr}^{2+}: \mathrm{ZnS}$ IR transparent ceramics (67\% transmittance at $\left.11.6 \mu \mathrm{m}\right)$ was successfully fabricated via vacuum hot pressing by consolidating colloidally processed $\mathrm{ZnS}$ 
powders mixed with commercially sourced $\mathrm{Cr}_{2} \mathrm{~S}_{3}$ powders. The $\mathrm{Cr}^{2+}: \mathrm{ZnS}$ ceramics were determined to be primarily composed of cubic $\mathrm{ZnS}$ sphalerite phase, with hexagonal $\mathrm{ZnS}$ wurtzite as a minor phase. It was demonstrated that the well-dispersed and homogenous morphology of the raw powders combined with the effects of VHP led to highly effective consolidation of the $\mathrm{Cr}^{2+}: \mathrm{ZnS}$ powders into high-transparency ceramics. IR absorption analysis demonstrated that $\mathrm{Cr}^{2+}$ ions were incorporated into the $\mathrm{ZnS}$ lattice, and the concentration of $\mathrm{Cr}^{2+}$ in the VHP-sintered $\mathrm{Cr}^{2+}: \mathrm{ZnS}$ ceramic was estimated to be $1.8 \cdot 10^{18} \mathrm{~cm}^{-3}$. Characterization of the IR photoluminescence emission and kinetics of the VHP-sintered ceramic revealed the corresponding ${ }^{5} \mathrm{E} \rightarrow{ }^{5} \mathrm{~T}_{2}$ characteristic bands of $\mathrm{Cr}^{2+}$ in $\mathrm{ZnS}$, and further confirmed the existence of tetrahedrally coordinated $\mathrm{Cr}^{2+}$ within the $\mathrm{ZnS}$ host lattice. Further studies focused on decreasing scattering effects in VHP-sintered $\mathrm{Cr}^{2+}: \mathrm{ZnS}$ are required to improve the optical performance of the material to increase its suitability for mid-IR laser applications.

Dr. Wu's group (Yiyu Li, Yin Liu, and Yiquan Wu) developed and processed hot-pressed ceramics. Dr. Mirov's group (Dr. Fedorov and Dr. Mirov) collaborated in spectroscopic characterizations of the samples.

Yiyu Li and Yiquan Wu gratefully acknowledge the Office of Naval Research (contract N00014-14-1-0546) for partially funding this research. Yin Liu and Yiquan Wu also gratefully acknowledge the US Air Force Office of Scientific Research (contract FA9550-14-1-0155) for partially funding their work.

The work performed by Dr. Mirov and Dr. Fedorov partially involves intellectual property developed at the University of Alabama at Birmingham (UAB). This intellectual property has been licensed to the IPG Photonics Corporation. Drs. Mirov and Fedorov declare competing financial interests and would like to acknowledge funding support from the AF Office of Scientific Research (Award No. FA9550-13-1-0234) and DARPA contract W31P4Q-15-1-0008.

\section{References:}

[1] D.C. Harris, Materials for Infrared Windows and Domes: Properties and Performance, SPIE Press, Bellingham, 1999.

[2] X.S. Fang, T.Y. Zhai, U.K. Gautam, L. Li, L.M. Wu, Y. Bando, D. Golberg, Prog. Mater. Sci. 56 (2011) 175. 
[3] J.-H. Song, T. Atay, S. Shi, H. Urabe, A.V. Nurmikko, Nano Lett. 5 (2005) 1557.

[4] A. Kudo, M. Sekizawa, Chem. Commun. (2000) 1371.

[5] H. Hu, W. Zhang, Opt. Mater. 28 (2006) 536.

[6] A.A. Khosravi, M. Kundu, L. Jatwa, S. Deshpande, U. Bhagwat, M. Sastry, S. Kulkarni, Appl. Phys. Lett. 67 (1995) 2702.

[7] P. Yang, M. Lü, D. Xü, D. Yuan, J. Chang, G. Zhou, M. Pan, Appl. Phys. A Mater. Sci. Process. 74 (2002) 257.

[8] Y. Li, Y. Wu, Opt. Mater. 49 (2015) 100.

[9] S. Ummartyotin, N. Bunnak, J. Juntaro, M. Sain, H. Manuspiya, Solid State Sci. 14 (2012) 299.

[10] L.D. DeLoach, R.H. Page, G.D. Wilke, S. Payne, W.F. Krupke, Ieee. J. Quantum. Elect. 32 (1996) 885 .

[11] S.B. Mirov, V.V. Fedorov, I.S. Moskalev, D.V. Martyshkin, IEEE J. Sel. Top. Quantum Electron. 13 (2007) 810.

[12] S. Mirov, V. Fedorov, D. Martyshkin, I. Moskalev, M. Mirov, V. Gapontsev, Opt. Mater. Express 1 (2011) 898.

[13] K. Graham, S.B. Mirov, V.V. Fedorov, M.E. Zvanut, A.G. Avanesov, V.V. Badikov, B. Ignat'ev, V. Panutin, G.S. Shevyrdayeva, Laser performance of $\mathrm{Cr}^{2+}$-doped ZnS, in: Proc. SPIE 4267, Solid State Lasers X, International Society for Optics and Photonics, Bellingham, 2001, pp. 81.

[14] S.B. Mirov, V.V. Fedorov, D. Martyshkin, I.S. Moskalev, M. Mirov, S. Vasilyev, IEEE J. Sel. Top. Quantum Electron. 21 (2015) 292.

[15] I. Moskalev, V. Fedorov, S. Mirov, Opt. Express 17 (2009) 2048.

[16] S. Wang, S.B. Mirov, V.V. Fedorov, R.P. Camata, Synthesis and spectroscopic properties of Cr-doped ZnS crystalline thin films, in: Proc. SPIE 5332, Solid State Lasers XIII: Technology and Devices, International Society for Optics and Photonics, Bellingham, 2004, pp. 13.

[17] D. Martyshkin, V. Fedorov, C. Kim, I. Moskalev, S. Mirov, J. Opt. 12 (2010) 024005.

[18] N. Tolstik, E. Sorokin, I.T. Sorokina, Opt. Lett. 38 (2013) 299.

[19] E. Sorokin, N. Tolstik, I.T. Sorokina, 1 Watt femtosecond mid-IR Cr:ZnS laser, in: Proc. SPIE 8599, Solid State Lasers XXII: Technology and Devices, International Society for Optics and Photonics, Bellingham, 2013, pp. 859916.

[20] S. Vasilyev, M. Mirov, V. Gapontsev, Opt. Express 22 (2014) 5118.

[21] S. Vasilyev, I. Moskalev, M. Mirov, S. Mirov, V. Gapontsev, Opt. Lett. 40 (2015) 5054.

[22] S. Vasilyev, I. Moskalev, M. Mirov, S. Mirov, V. Gapontsev, Opt. Express 24 (2016) 1616.

[23] N. Vlasenko, P. Oleksenko, M. Mukhlyo, L. Veligura, Z. Denisova, Semicond. Phys. Quantum Electron. Optoelectron. 12 (2009) 362.

[24] M. Nematollahi, X. Yang, L.M.S. Aas, Z. Ghadyani, M. Kildemo, U.J. Gibson, T.W. Reenaas, Sol. Energ. Mater. Sol. C. 141 (2015) 322.

[25] T. Xiao-Ming, K. Xiao-Yu, Z. Kang-Wei, Solid State Commun. 136 (2005) 395.

[26] M.G. Brik, First-principles calculations of crystal field effects and absorption spectra for 3d ions in laser crystals, in N.M. Avram, M.G. Brik (Eds.),Optical Properties of 3d-Ions in Crystals: Spectroscopy and Crystal Field Analysis, Springer, Berlin, 2013, pp. 203-250.

[27] S.B. Mirov, V.V. Fedorov, Mid-IR microchip laser: $\mathrm{ZnS}: \mathrm{Cr}^{2+}$ laser with saturable absorber material, US8767789 B2, 2005.

[28] M. Chen, H. Cui, W. Li, H. Kou, J. Li, Y. Pan, B. Jiang, J. Alloy. Compd. 597 (2014) 124.

[29] L. Esposito, A. Piancastelli, S. Martelli, J. Eur. Ceram. Soc. 33 (2013) 737. 
[30] C. Chlique, O. Merdrignac-Conanec, N. Hakmeh, X. Zhang, J.L. Adam, J. Am. Ceram. Soc. 96 (2013) 3070.

[31] Y. Li, Y. Wu, J. Am. Ceram. Soc. (2015).

[32] Z. Liu, B. Mei, J. Song, W. Li, J. Am. Ceram. Soc. 97 (2014) 2506.

[33] W. Kim, G. Villalobos, C. Baker, J. Frantz, B. Shaw, S. Bayya, B. Sadowski, M. Hunt, B. Rock, I. Aggarwal, Appl. Optics 54 (2015) F210.

[34] S. Dutta, G. Gazza, Mater. Res. Bull. 4 (1969) 791.

[35] W. Kim, C. Baker, S. Bowman, C. Florea, G. Villalobos, B. Shaw, B. Sadowski, M. Hunt, I. Aggarwal, J. Sanghera, Opt. Mater. Express 3 (2013) 913.

[36] W. Kim, C. Baker, G. Villalobos, J. Frantz, B. Shaw, J. Sanghera, B. Sadowski, I. Aggarwal, J. Dir. Energy 5 (2013) 93.

[37] A. Gallian, V.V. Fedorov, S.B. Mirov, V.V. Badikov, S.N. Galkin, E.F. Voronkin, A.I. Lalayants, Opt. Express 14 (2006) 11694.

[38] G. Grebe, H.-J. Schulz, Z. Naturforsch. A Phys. Sci. 29 (1974) 1803.

[39] S. Mirov, V. Fedorov, K. Graham, I. Moskalev, I. Sorokina, E. Sorokin, V. Gapontsev, D. Gapontsev, V. Badikov, V. Panyutin, IEE Proc. Optoelectron. 150 (2003) 340.

[40] H. Nelkowski, G. Grebe, J. Lumin. 1 (1970) 88.

[41] B. Henderson, R.H. Bartram, Crystal-Field Engineering of Solid-State Laser Materials, Cambridge University Press, Cambridge, 2005.

[42] I.T. Sorokina, E. Sorokin, S. Mirov, V. Fedorov, V. Badikov, V. Panyutin, A. Di Lieto, M. Tonelli, Appl. Phys. B: Lasers Opt. 74 (2002) 607.

[43] C.S. Kelley, F. Williams, Phys. Rev. B 2 (1970) 3. 
Graphical Abstract

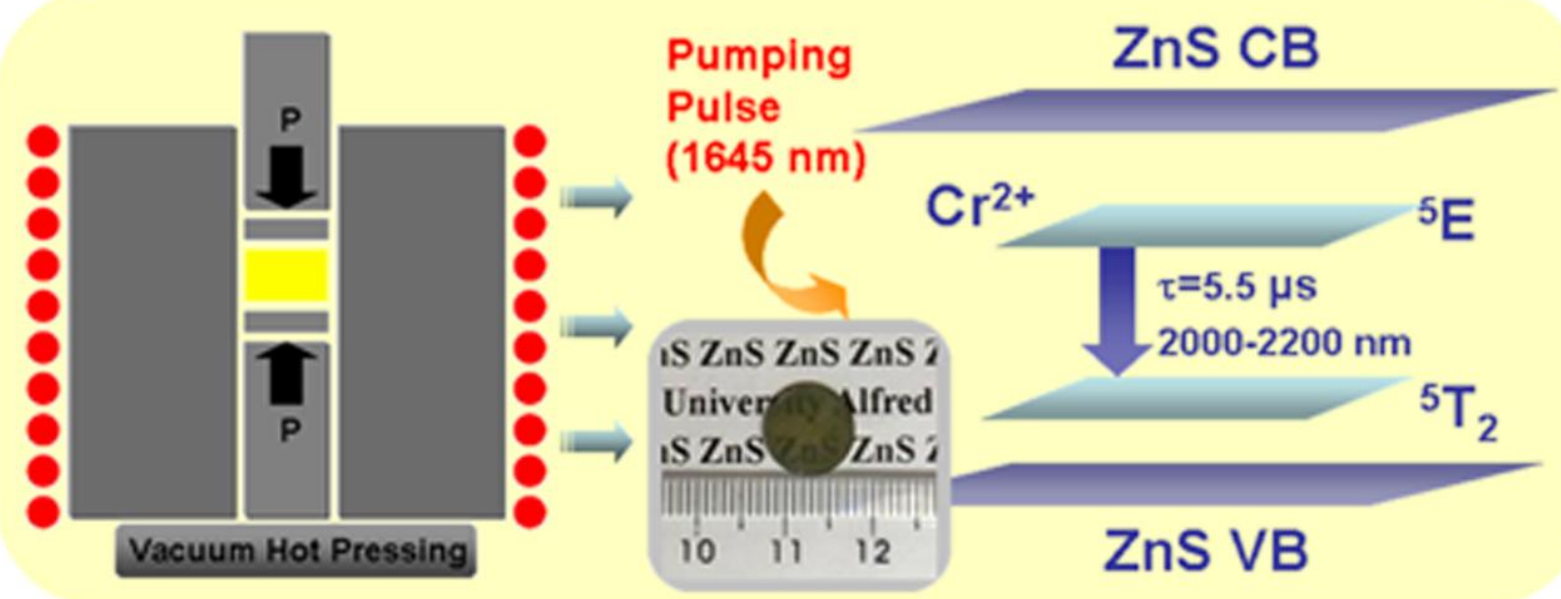

